\title{
Evidence of Neuromonitoring and Decision-Making during Thyroidectomy: Case Report
}

\author{
Alberto Robles Méndez Hernández ${ }^{1 *}$, Oscar Alejandro Mora Torres ${ }^{2}$, Roberto Ramírez \\ Hernández ${ }^{1}$, Marco Antonio Ramírez García ${ }^{1}$, Sandra Berenice Somarriba Domínguez ${ }^{1}$, \\ Fernando Eduardo Fuentes Muñoz ${ }^{2}$ \\ ${ }^{I}$ General Surgery Service, Hospital Angeles Metropolitano, Mexico City, Mexico \\ ${ }^{2}$ General Surgery Service, Hospital Angeles Lomas, Mexico City, Mexico \\ *Corresponding Author: Alberto Robles Méndez Hernández, General Surgery Service, Hospital Ángeles \\ Metropolitano, Tlacotalpan \#59, Mexico City, Mexico.
}

\begin{abstract}
Summary
Thyroidectomy is one of the most frequently performed procedures in neck surgery, the close anatomical relationship with multiple vital structures has sought the innovation of the procedure in the search for safe surgery including neuromonitoring. The objective of this article is to show the evidence regarding the use of neuromonitoring when we have suspected trans-surgical nerve injury.
\end{abstract}

Case Report: A 58 -year-old female protocolized for total Thyroidectomy for papillary cancer. During surgery, its initially approached on the left side, recurrent laryngeal nerve is identified and after Berry ligament dissection, signal is lost, after 2 minutes intact nerve is corroborated, equipment failure was identified with signal recovery, the total thyroidectomy is completed.

Conclusions: Neuromonitoring can be a great trans-surgical tool for high risk patients. Broad communication must be maintained, which intervenes with its use and interpretation. Equipment failure can contribute interpretation bias that modifies the course of surgery and disease.

Keywords: Total Thyroidectomy, neuromonitoring, thyroid cancer.

\section{BACKGROUND}

Thyroidectomy is the resection of the thyroid gland; this can be performed on an ambulatory way [1] without significantly increasing the morbidity of the procedure. Intraoperative neuromonitoring has been used in thyroid surgery to identify the recurrent laryngeal nerve and the superior laryngeal nerve, has high specificity $(99.4 \%)$ and negative predictive value $(99.8 \%)$ in addition to good sensitivity $(93.6 \%)$ and positive predictive value (78.4\%), [2] allows the surgeon to detect the first data of nerve injury, which is initially reversible.[3] In addition to effectively identifying anatomical nerve variants, resulting in visualization of areas with the highest vulnerability for dissection. (Berry ligament, Zuckerkandl Tubercle and inferior thyroid artery). [4]

\section{CASE Report}

A 42 year-old female protocolized for Total thyroidectomy for papillary cancer due to fineneedle aspiration biopsy by a $0.5 \mathrm{~cm}$ diameter normal - functioning nodule classified as Bethesda $\mathrm{V}$ of papillary line in the upper portion of the left lobe and multiple follicular lesions in the right lobe and multiple follicular lesions in the right lobe, therefore entering the operating room on suspicion of oncological pathology. During surgery, the left side was initially approached, recurrent laryngeal nerve was identified and after Berry ligament dissection, neuromonitoring signal was lost, the possibility of ending in hemithyroidectomy was raised, and within 2 minutes intact nerve was corroborated, equipment failure was identified with recovery of nerve signal seen in image 3 and the total thyroidectomy is completed. In image 1 and 2 we can see trans-surgery image of lymph node disease and dissection zones, and image 4 macroscopical view of thyroid gland reviewed in which previously mentioned nodules are observed; the definitive histopathological report provides a diagnosis of papillary cancer. The patient is monitored monthly for two years after radioactive iodine therapy, there is no evidence of disease activity or language disorder. 


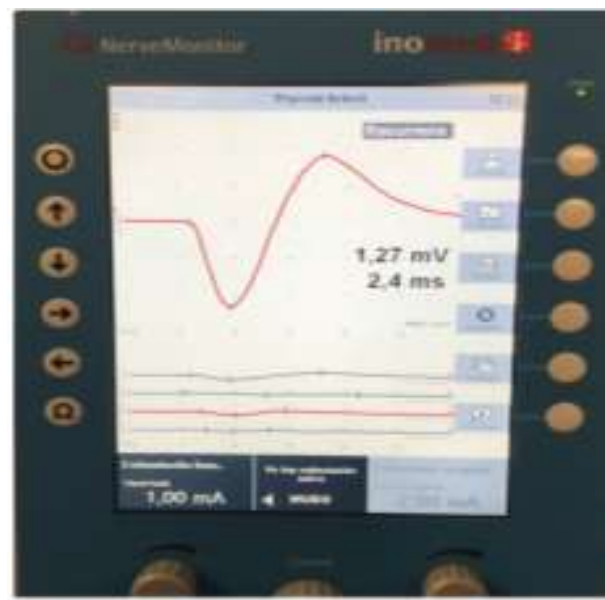

Image 1. Neuromonitor screen revealing recurrent laryngeal nerve signal after equipment failure

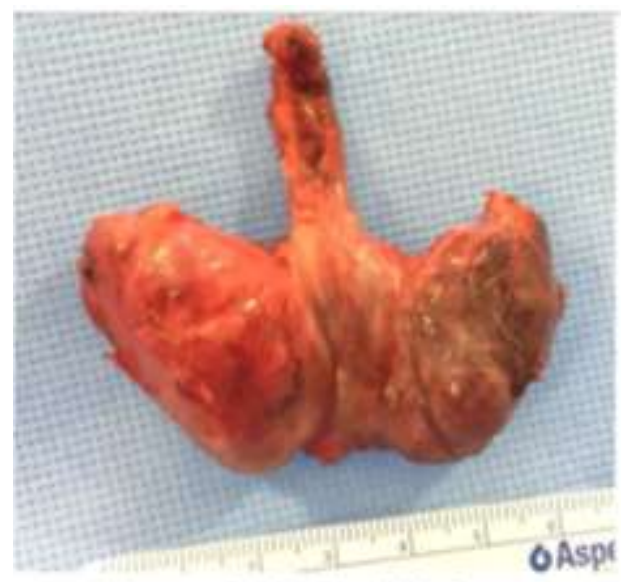

Image 2. Macroncepical wiew of thyedid gland



image 1 Transurgieal image ef lymph nedte dismase

\section{DISCUSSION}

If neuromonitoring is used, the signal loss would indicate an intraoperative change in the surgical plan, for a two-stage approach for total thyroidectomy. The use of routine neuromonitoring in thyroidectomy is not recommended, except in high-risk patients [5] in which at no time does it replace nerve identification and surgical technique, [6] its use does not show statistical difference in both transient recurrent laryngeal nerve injuries ( $2.62 \%$ vs 2.72 )as permanent ( $0.79 \%$ vs $0.92 \%)$.

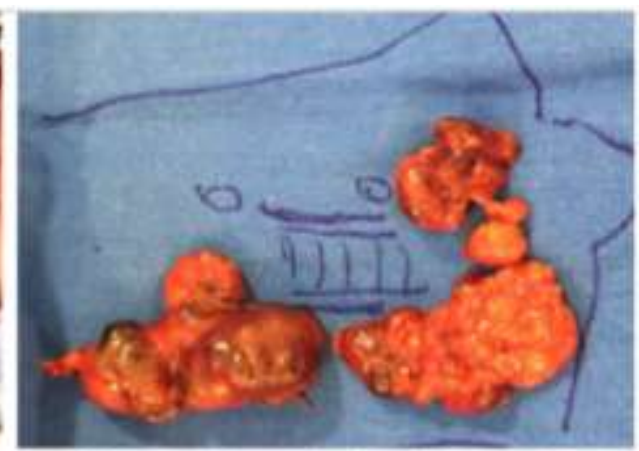

Imaeg 4. Transurgicat scheme of Nymoh node thease and dissection

[7] In patients with signal loss (LOS) in neuromonitoring during thyroidectomy $(2.7 \%)$,

It was decided to perform the thyroidectomy in two phases. $95.7 \%$ of these patients presented unilateral transient paralysis on recurrent laryngeal, while the rest were permanent. [8]

In postoperative patients with total thyroidectomy, the use of ketamine $(1 \mathrm{mg} / \mathrm{kg})$ instilled into the wound significantly reduces the total morphine required, as well as delays the first use of analgesia, being associated less frequently with adverse effects. [9] The 
procedure significantly improves the quality of life in patients with hyper functioning pathology. [10]

Hypocalcaemia is present in $38 \%$ of the patients with total thyroidectomy during the immediate postoperative period, which is significantly associated with proportional levels of hypomagnesemia. The serum magnesium curve in these patients presents similar variations to the serum calcium curve. [11]. The main mechanism that generates hipocalcemia in these patients is relative parathyroid insufficiency, even with normal levels of parathyroid hormone. [12]

Minimally invasive video assisted thyroidectomy presents a safe and effective alternative in selected patients, since it reduces the rate of complications and postoperative pain, in addition to improving aesthetic results and patient satisfaction. However, for its correct application, deep training is necessary. [13] With an incidence of transient recurrent laryngeal nerve palsy of $5.12 \%$ among the total number of nerves at risk, and $0 \%$ of permanent palsy. [14]

There is little evidence of the use of neuromonitoring in low-risk patients. Although in suspicion of anatomical loss, it can be very useful in reducing post-surgical morbidity by not only preventing direct injuries, but also by reducing the manipulation of tissues near nerve structures.

\section{CONCLUSiON}

Neuromonitoring can be a great tool during the surgery for previously selected high-risk patients. Broad communication must be maintained that intervenes with its use and interpretation. The failure of equipment and experience can provide sufficient bias in the interpretation of neuromonitoring that modifies the course of the surgery and disease.

\section{FUNDING AND CONFLICTS OF INTEREST}

None

\section{ETHICAL APPROVAL}

There was no ethics approval required for this case report

\section{CONSENT}

Written informed consent was obtained from the patient for publication of this case report and accompanying images

\section{REFERENCES}

[1] Reinhart HA, Snyder SK, Stafford SV, Wagner VE, Graham CW, Bortz MD, et al. Same day discharge after thyroidectomy is safe and effective. Surgery. 2018 Oct;164(4):887-94.

[2] Calò PG, Medas F, Conzo G, Podda F, Canu GL, Gambardella $\mathrm{C}$, et al. Intraoperative neuromonitoring in thyroid surgery: Is the twostaged thyroidectomy justified? Int J Surg. 2017 May;41:S13-20.

[3] Julien N, Ferrary E, Sokoloff A, Lamas G, Sterkers O, Bernardeschi D. Vagal and recurrent laryngeal nerves neuromonitoring during thyroidectomy and parathyroidectomy: A prospective study. Eur Ann Otorhinolaryngol Head Neck Dis. 2017 Apr;134(2):77-82.

[4] Wojtczak B, Kaliszewski K, Sutkowski K, Bolanowski M, Barczyński M. A functional assessment of anatomical variants of the recurrent laryngeal nerve during thyroidectomies using neuromonitoring. Endocrine. 2018 Jan;59(1):82-9.

[5] Wong MP-K, Zahari Z, Abdullah MS, Ramely R, Md Hashim MN, Zakaria Z, et al. Postoperative major surgery patients developing silent deep vein thrombosis: A prospective observational study. J Vasc Nurs. 2018 Dec;36(4):173-80.

[6] Chan W-F, Lo C-Y. Pitfalls of Intraoperative Neuromonitoring for Predicting Postoperative Recurrent Laryngeal Nerve Function during Thyroidectomy. World J Surg. 2006 May;30(5):806-12.

[7] Pisanu A, Porceddu G, Podda M, Cois A, Uccheddu A. Systematic review with metaanalysis of studies comparing intraoperative neuromonitoring of recurrent laryngeal nerves versus visualization alone during $\begin{array}{lllll}\text { thyroidectomy. J } & \text { Surg }\end{array}$ May;188(1):152-61.

[8] Christoforides C, Papandrikos I, Polyzois G, Roukounakis N, Dionigi G, Vamvakidis K. Two-stage thyroidectomy in the era of intraoperative neuromonitoring. Gland Surg. 2017 Oct;6(5):453-63.

[9] Abd EL-Rahman AM, El Sherif FA. Efficacy of Postoperative Analgesia of Local Ketamine Wound Instillation Following Total Thyroidectomy; A Randomized, Double-blind, Controlled-clinical Trial: Clin J Pain. 2017 Jun;1.

[10] Kus LH, Hopman WM, Witterick IJ, FreemanFreemanFreeman JL. Quality-of-Life Outcomes in Graves Disease Patients after Total Thyroidectomy. Ear Nose Throat J. 2017 Apr;96(4-5):E8-9. 
[11] Mahmoud RR da GL, Neto VJF de A, Alves W, Lin CS, Leite AKN, Matos LL, et al. Hypomagnesemia associated with hypocalcemia after total thyroidectomy: an observational study. Magnes Res. 2016 Jun;(2):43-47.

[12] Raffaelli M, De Crea C, D'Amato G, Moscato $\mathrm{U}$, Bellantone $\mathrm{C}$, Carrozza $\mathrm{C}$, et al. Postthyroidectomy hypocalcemia is related to parathyroid dysfunction even in patients with normal parathyroid hormone concentrations early after surgery. Surgery. 2016 Jan;159(1):78-85.
[13] Lombardi CP, Carnassale G, D'Amore A, Milano V, De Crea C, Raffaelli M, et al. Morbidity from minimally invasive videoassisted thyroidectomy: a general review. Gland Surg. 2017 Oct;6(5):488-91.

[14] Zhang D, Li F, Wu C-W, Liu X, Xin J, Chiang F-Y, et al. Percutaneous probe stimulation for intraoperative neuromonitoring in total endoscopic thyroidectomy: A preliminary experience: Intraoperative neuromonitoring in total endoscopic thyroidectomy. Head Neck. 2017 May;39(5):1001-7.

Citation: Alberto Robles Méndez Hernández, Oscar Alejandro Mora Torres, Roberto Ramírez Hernández, Marco Antonio Ramírez García, Sandra Berenice Somarriba Domínguez, Fernando Eduardo Fuentes Muñoz. Evidence of Neuromonitoring and Decision-Making during Thyroidectomy: Case Report. ARC Journal of Surgery. 2020; 6(1):4-7. DOI: http://dx.doi.org/ 10.20431/2455-572X.0601002.

Copyright: (C) 2020 Authors. This is an open-access article distributed under the terms of the Creative Commons Attribution License, which permits unrestricted use, distribution, and reproduction in any medium, provided the original author and source are credited. 